\title{
A nationwide epidemiological survey of spinal cord injuries in Japan from January 1990 to December 1992
}

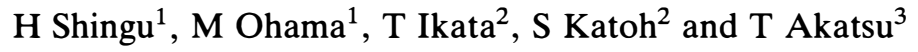 \\ Prevention Committee of Japan Medical Society of Paraplegia, ${ }^{1}$ Department of Orthopaedic Surgery, San-in \\ Rosai Hospital, 1-8-1 Kaikeshinden, Yonago 683; ${ }^{2}$ Department of Orthopaedic Surgery, Tokushima University \\ School of Medicine, Tokushima 770; ${ }^{3}$ Spinal Injuries Centre, Iizuka 820, Japan
}

\begin{abstract}
This survey of traumatic spinal cord injuries in Japan from January 1990 to December 1992 was carried out by a statistical method of the nationwide epidemiological study. The number of the registered patients during these 3 years was 9752 and the mean response rate of every of the 47 prefectures was $51.4 \%$. The registered patients with neurological deficits (Frankel A-D) were 7471 and the annual spinal cord injury incidence was 40.2 per million. The ratio of cervical cord injuries to more caudal SCI was 3:1. The age distribution and the causes of spinal cord injuries are presented in detail. From the results of this study, the prevention campaign should be focused mainly on the following topics: sports and motorcycle accidents involving young people; traffic accidents involving adults; falling accidents involving aged people.
\end{abstract}

Keywords: spinal cord injury; Japan; epidemiology; incidence; prevention; etiology

\section{Introduction}

The Spinal Cord Injury Prevention Committee of the Japan Medical Society of Paraplegia (JMSOP) started a nationwide epidemiological survey using a postal questionnaire in 1990. The results obtained were reported previously. ${ }^{1}$ The following description provides an overview of the 9752 traumatic spinal cord injuries (SCI) which were reported from January 11990 to December 311992 (3 years).

\section{Materials and methods}

The Spinal Cord Injury Prevention Programme Subcommittee of JMSOP and the regional supervisors of JMSOP sent out study charts in the form of questionnaires by mail to all departments of orthopaedic surgery, neurosurgery and rehabilitation and emergency medical service centres in medical institutions throughout the country, which were assumed to accept SCI, and asked these departments to return the filled-in questionnaire to the supervisor in each region. The departments which had no SCI were also asked to reply.

Concerning the severity of injury, patients with paralysis and paresis as well as those suffering only from numbness without motor paralysis were included.

Using the statistical method of the nationwide epidemiological survey, ${ }^{2}$ the annual estimated incidence was obtained from the number of patients

Correspondence: Dr H Shingu, Director San-in Rosai Hospital, 1-8-1 Kaikeshinden, Yonago 683, Japan registered and the questionnaire response rate in each prefecture on a regional basis (with the confidence limit of over $90 \%$ ).

Estimated SCI number $=$

$$
\Sigma \frac{\text { Registered SCI number in each prefecture }}{\text { Response rate in each prefecture }}
$$

There are 47 prefectures in Japan. Only those who were injured between the 1st of January 1990 and the 31st of December 1992 were accepted for the study. Those who were treated only on an outpatient basis were excluded. The neurological deficits were classified according to the Frankel classification. ${ }^{3}$

\section{Results}

The study charts in the form of a questionnaire were sent to 9270 departments in 1990, 8619 in 1991 and 8577 in 1992. The mean response rate of each of the 47 prefectures was $51.4 \%$.

\section{Incidence}

A total of $9752 \mathrm{SCI}$ in this 3-year period was registered (Table 1). Excluding Frankel E, there were 7471 cases in Frankel A, B, C and D and the number estimated from the response rate was 14968. As the exposed population in Japan over 3 years was 372.10 million, the incidence of SCI estimated from the number of patients registered and the reply rate was 40.2 per million per annum (Table 2). 
Sex and age

There were 7842 male and 1909 female patients. The number of males was about four times as large as that of females.

The age at the time of injury was from 11 months to 96 years. The mean age with a standard deviation was $48.6 \pm 19.1$ years. The age distribution showed a diphasic feature, with a main peak at 59 years of age, and an additional small peak at 20 years of age (Figure 1).

\section{Level of injury}

Of the registered 9752 cases, cervical cord injuries occurred in 7317 patients $(75.0 \%)$ and caudal to the cervical region, there were 2408 patients $(24.7 \%)$, with the incidence of the former being three times as much as that of the latter. Otherwise, unknown cases were 27 $(0.3 \%)$. The mean age at the time of injury was 51 years in those with cervical cord injury, and 40 years for those with more caudal SCI. Comparison of the severity of neurological deficits revealed that complete neuro-

Table 1 Neurological status of registered patients

\begin{tabular}{lccrr}
\hline Frankel grade & 1990 & 1991 & 1992 & Total \\
\hline A & $921(26.6 \%)$ & $783(25.3 \%)$ & $814(25.5 \%)$ & $2518(25.8 \%)$ \\
B & $433(12.5 \%)$ & $334(10.8 \%)$ & $441(13.8 \%)$ & $1208(12.4 \%)$ \\
C & $692(20.0 \%)$ & $665(21.5 \%)$ & $627(19.7 \%)$ & $1984(20.3 \%)$ \\
D & $619(17.9 \%)$ & $590(19.0 \%)$ & $552(17.3 \%)$ & $1761(18.1 \%)$ \\
E & $792(22.8 \%)$ & $715(23.1 \%)$ & $735(23.0 \%)$ & $2242(23.0 \%)$ \\
Unknown & $8(0.2 \%)$ & $10(0.3 \%)$ & $21(0.7 \%)$ & $39(0.4 \%)$ \\
Total & $3465(100 \%)$ & $3097(100 \%)$ & $3190(100 \%)$ & $9752(100 \%)$ \\
\hline
\end{tabular}

Table 2 Incidence of spinal cord injury

\begin{tabular}{lcccc}
\hline & 1990 & 1991 & 1992 & Total \\
\hline Population (million) & 123.61 & 124.04 & 124.45 & 372.10 \\
Number of departments & 9270 & 8619 & 8577 & 26466 \\
Response rate & $56.6 \%$ & $48.3 \%$ & $49.0 \%$ & $51.4 \%$ \\
Registered number & 3465 & 3097 & 3190 & 9752 \\
Frankel grades A-D & 2665 & 2372 & 2434 & 7471 \\
$\quad$ Registered number & 4872 & 4986 & 5110 & 14968 \\
$\quad$ Estimated number & 39.4 & 40.2 & 41.1 & 40.2 \\
$\quad$ Incidence (per million) & & & & \\
\hline
\end{tabular}

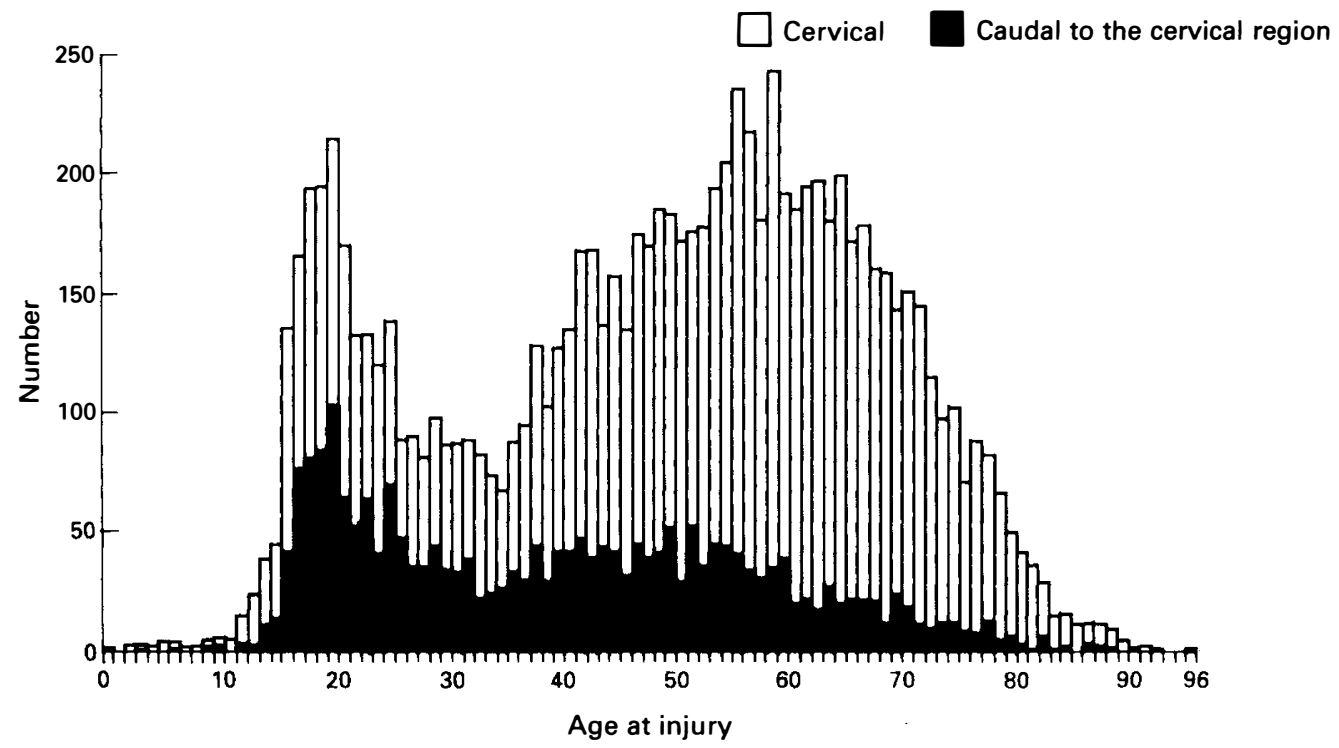

Figure 1 Age distribution at the time of injury 
logical lesions accounted for $21.2 \%$ of those with cervical SCI and $39.9 \%$ for those with more caudal SCI.

\section{Causes of injury}

The most frequent cause of injury was a traffic accident $(43.7 \%)$, followed by falls from a height $(28.9 \%)$. Although there is some difficulty in distinguishing 'falls from a height' from 'falls on level ground', there was $12.9 \%$ with a SCI from a fall on level ground, including a fall down a few stair steps (Table 3 ).

The three major causes of cervical cord injury were traffic accidents, falls from a height and falls on level ground, while SCI caudal to the cervical region was mainly due to falls from a height, followed by traffic accidents and being struck by an object.

\section{Age at the time of injury}

Regarding the mean age at the time of injury and the causes of injuries, sports accident injuries occurred at 28.5 years, traffic accident injuries at 44.4 years, being struck by an object at 48.3 years, falls from a height at 53.2 years, and falls on level ground at 61.7 years. Traffic accidents and sports accidents were the most frequent causes of injury amongst younger people, while falls from a height and falls on level ground occurred more often in elderly people (Figure 2).

\section{Traffic accidents}

In those with SCI caused by traffic accidents, automobiles, motorcycles, bicycles and pedestrians were responsible respectively for $47.1,29.1,15.6$ and $5.9 \%$ (Table 4).

\section{Seatbelt use and neurological function}

A question asking whether a SCI occurred in a motor vehicle accident whilst the individual was or was not wearing a seatbelt was included in the questionnaire. A significant difference of complete deficit ratio was found between these two groups of seatbelt users and non-users $(P<0.05)$; that is, $19.6 \%(55 / 281)$ of seatbelt users sustained a complete deficit Frankel A, while $29.8 \%(120 / 403)$ of non-users had a complete neurological deficit (Figure 3).

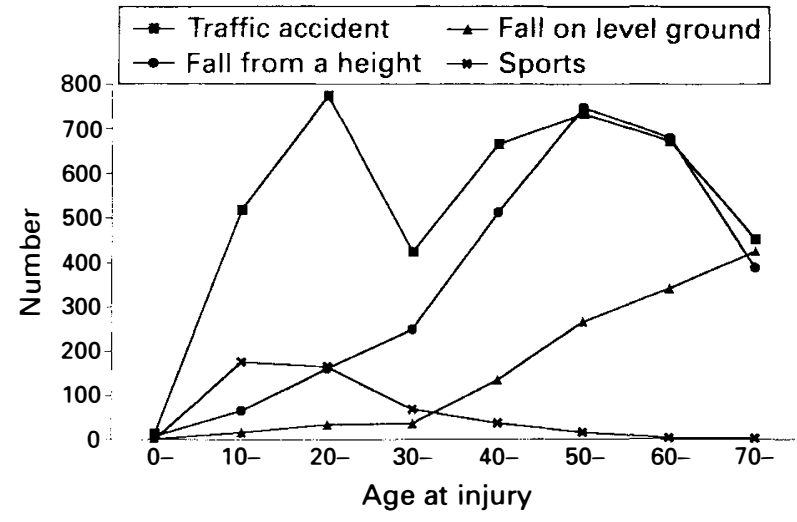

Figure 2 Age distribution by causes of injury

Table 4 Analysis of traffic accidents

\begin{tabular}{lrrrc}
\hline & 1990 & 1991 & 1992 & Total \\
\hline Car & 709 & 585 & 713 & $2007(47.1 \%)$ \\
Motorcycle & 466 & 388 & 385 & $1239(29.1 \%)$ \\
Bicycle & 240 & 217 & 206 & $663(15.6 \%)$ \\
Pedestrian & 86 & 84 & 80 & $250(5.9 \%)$ \\
Others & 46 & 34 & 24 & $104(2.4 \%)$ \\
Total & 1547 & 1308 & 1408 & $4263(100 \%)$ \\
\hline
\end{tabular}

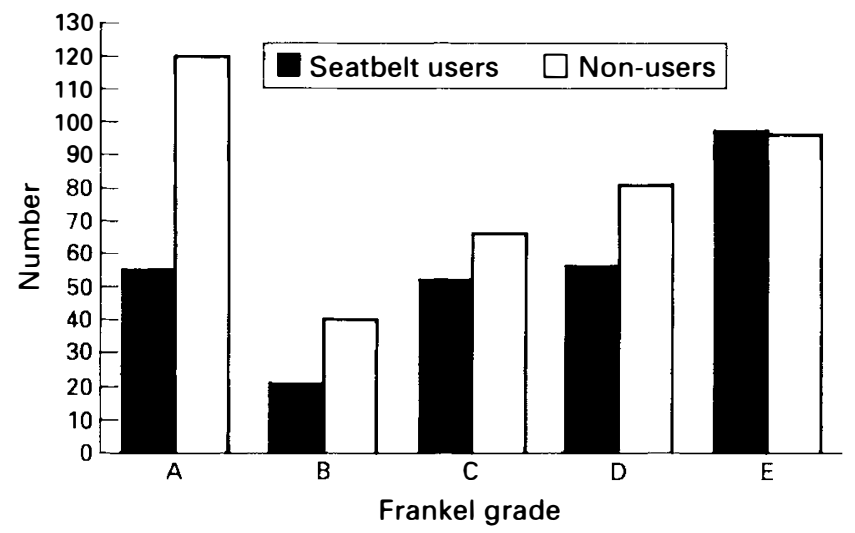

Figure 3 The extent of neurological injury and its correlation with wearing a seatbelt in a motor vehicle accident

\section{Industrial accidents}

There were 1831 patients who had had an industrial accident, accounting for $18.8 \%$ of the total cases. The

Table 3 Cause of spinal cord injuries and the mean age at the time of injury

\begin{tabular}{|c|c|c|c|c|c|}
\hline Cause of injury & 1990 & 1991 & 1992 & Total & $\begin{array}{c}\text { Age at injury } \\
\text { (years) }\end{array}$ \\
\hline Traffic accident & 1547 & 1308 & 1408 & $4263(43.7 \%)$ & 44.4 \\
\hline Fall from a height & 1012 & 912 & 894 & $2818(28.9 \%)$ & 53.2 \\
\hline Fall on level ground & 407 & 417 & 436 & $1260(12.9 \%)$ & 61.7 \\
\hline Being struck by object & 209 & 169 & 159 & $537(5.5 \%)$ & 48.3 \\
\hline Sports accident & 182 & 174 & 172 & $528(5.4 \%)$ & 28.5 \\
\hline Attempted suicide & 60 & 63 & 44 & $167(1.7 \%)$ & 31.9 \\
\hline Other & 48 & 54 & 77 & $179(1.9 \%)$ & 47.3 \\
\hline Total & 3465 & 3097 & 3190 & $9752(100 \%)$ & 48.6 \\
\hline
\end{tabular}


186

causes of these SCIs were falls from a height (50.6\%), traffic accidents $(21.8 \%)$ including commuting accidents, and injury by being under heavy objects and wreckage $(19.0 \%)$. Of these 1831 patients, cervical cord injuries accounted for $62.4 \%$, and caudal to the cervical region for $36.3 \%$ (Table 5).

\section{Sports accidents}

There were 528 sports accidents causing SCI, and the type of sport most frequently involved was diving, followed by skiing, rugby, gliding, judo, wrestling and gymnastics (Table 6). A total of 114 patients were injured by diving into shallow water, $75 \%$ of whom were under 24 years of age (Figure 4). These patients had a cervical SCI, with $47.8 \%$ having a complete spinal cord lesion.

\section{Influence of alcohol}

A question asked was whether the injury was influenced by drinking alcohol. The percentages of those thought to be under the influence of alcohol were $33.2 \%$ of those in bicycle accidents, $21.4 \%$ of pedestrian victims of traffic accidents and $24.6 \%$ of those who fell on level ground, which compared with the rates of alcohol influence from other causes (Figure 5).

\section{Discussion}

The Prevention Committee of the Japan Medical Society of Paraplegia prepared the plans for the accomplishment of a nationwide epidemiological survey and for the programmes for the prevention of spinal cord injury.

In the USA, Florida's central registry had collected data of SCI since 1978. ${ }^{4}$ The National Head and Spinal Cord Injury Prevention Programme was created in 1986 by the American Association of Neurological Surgeons and the Congress of Neurological Surgeons, and the name THINK FIRST ${ }^{5}$ was adopted as the programme's new identity in 1990. THINK FIRST symbolises the message of organised neurosurgery's prevention programme and the programmes are under way in communities throughout the USA.

Australia has six specialised spinal cord injury units. The Menzies Foundation has supported the creation of a national register to develop data and programmes for the prevention of SCI. ${ }^{6}$ This country, therefore, has the
Table 6 Sport and leisure activities resulting spinal cord injury

\begin{tabular}{lrrrr} 
& 1990 & 1991 & 1992 & Total \\
\cline { 1 - 2 } Diving & 44 & 32 & 38 & $114(21.6 \%)$ \\
Skiing & 20 & 26 & 25 & $71(13.4 \%)$ \\
Rugby & 24 & 21 & 22 & $67(12.7 \%)$ \\
Gliding & 11 & 12 & 14 & $37(7.0 \%)$ \\
Judo, wrestling & 11 & 11 & 13 & $35(6.6 \%)$ \\
Gymnastics & 14 & 5 & 12 & $31(5.9 \%)$ \\
Motor racing & 5 & 8 & 10 & $23(4.4 \%)$ \\
Baseball & 11 & 7 & 4 & $22(4.2 \%)$ \\
Others & 42 & 52 & 34 & $128(24.2 \%)$ \\
Total & 182 & 174 & 172 & $528(100 \%)$ \\
\hline
\end{tabular}

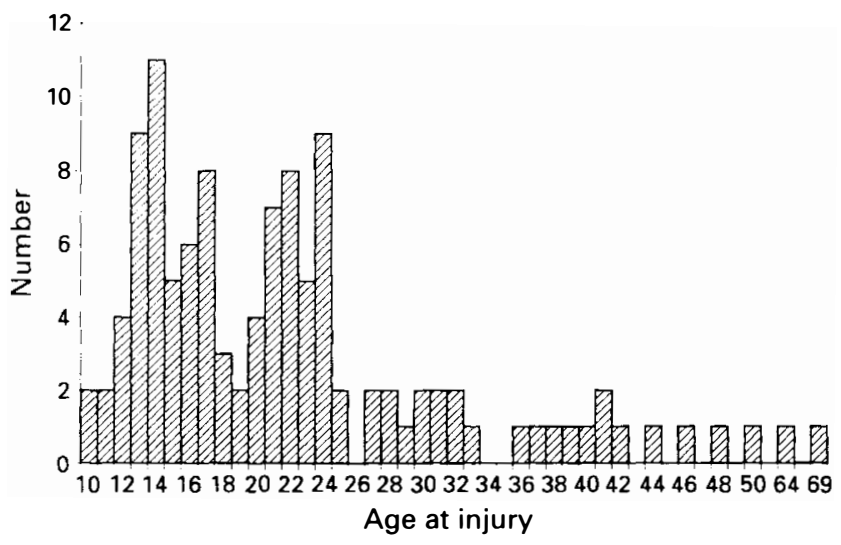

Figure 4 Age distribution in diving injuries

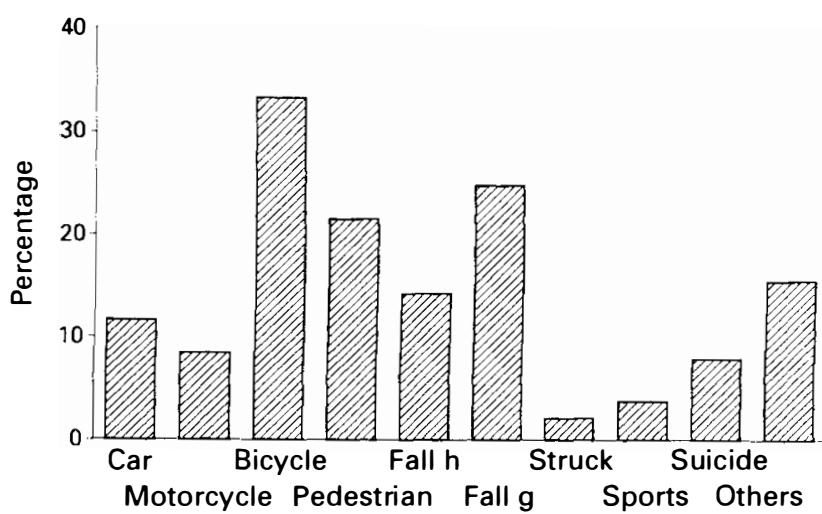

Figure 5 Ratios of SCI causes under influence of drinking alcohol. $\mathrm{h}=$ height; $\mathrm{g}=$ ground

Table 5 Industrial accidents

\begin{tabular}{lrrrr}
\hline Cause of injury & 1990 & 1991 & 1992 & Total \\
\hline Traffic accident & 157 & 113 & 129 & $399(21.8 \%)$ \\
Fall from a height & 338 & 303 & 285 & $926(50.6 \%)$ \\
Fall on level ground & 35 & 29 & 33 & $97(5.3 \%)$ \\
Being struck by object & 128 & 108 & 113 & $349(19.0 \%)$ \\
Sports & 9 & 6 & 7 & $22(1.2 \%)$ \\
Others & 6 & 17 & 15 & $38(2.1 \%)$ \\
Total & 673 & 576 & 582 & $1831(100 \%)$ \\
\hline
\end{tabular}


Table 7 Incidence of spinal cord injury in selected studies

\begin{tabular}{|c|c|c|c|c|c|c|}
\hline Authors and year & Region & $\begin{array}{l}\text { Population size } \\
\text { (millions) }\end{array}$ & Period of study & Number of SCI & $\begin{array}{c}\text { Incidence } \\
\text { (million/year) }\end{array}$ & Comments \\
\hline Gehrig $1968^{9}$ & Swiss & 5.5 & $1960-1967$ & 584 & 13.3 & $\begin{array}{l}\text { Identification based on questionnaire to } \\
\text { all hospitals with admissions of SCI }\end{array}$ \\
\hline Botterell $1975^{11}$ & Canada & 7.6 & $1969-1970$ & 224 & 14.7 & $\begin{array}{l}\text { Includes cases admitted to all hospitals in } \\
\text { Ontario }\end{array}$ \\
\hline Kraus $1975^{12}$ & California & 5.8 & $1970-1971$ & $\begin{array}{c}619 \\
(384)\end{array}$ & $\begin{array}{c}53.4 \\
(32.5)\end{array}$ & $\begin{array}{l}\text { Includes all cases regardless of severity } \\
\text { Only hospitalized cases }\end{array}$ \\
\hline Bracken $1981^{13}$ & USA & 206.4 & $1970-1977$ & 66204 & 40.1 & $\begin{array}{l}\text { Using National Hospital Discharge } \\
\text { Survey }\end{array}$ \\
\hline $\begin{array}{l}\text { Biering-Sørensen } \\
1990^{14}\end{array}$ & Denmark & 5.2 & $1975-1984$ & 268 & 9.2 & $\begin{array}{l}\text { Includes cases admitted to two specialised } \\
\text { rehabilitation hospitals }\end{array}$ \\
\hline Chen $1985^{15}$ & Taipei & 2.1 & $1978-1981$ & 123 & 14.6 & $\begin{array}{l}\text { Includes cases admitted to all general } \\
\text { hospitals in Taipei }\end{array}$ \\
\hline Burke $1987^{16}$ & Australia & 15.5 & $1981-1985$ & 1915 & 27.6 & $\begin{array}{l}\text { Includes cases identified from all } \\
\text { Australian spinal units }\end{array}$ \\
\hline Koening $1989^{17}$ & FRG & 61.5 & 1983 & 2213 & 36.0 & $\begin{array}{l}\text { From three sources, Central Office for } \\
\text { Paraplegia, workmen's compensation and } \\
\text { hospital discharge data }\end{array}$ \\
\hline DeLilla $1990^{4}$ & Florida & 11.9 & $1984-1988$ & 2138 & 36.0 & From the Florida's Central Registry \\
\hline Shingu $1994^{1}$ & Japan & 123.6 & $1990-1992$ & 9752 & 40.2 & $\begin{array}{l}\text { Using epidemiological survey based on } \\
\text { questionnaire to all hospitals with } \\
\text { admissions of SCI }\end{array}$ \\
\hline
\end{tabular}


potential for producing comprehensive statistical information and promoting prevention of SCI.,8

In Japan, historically, management of patients with SCI has been fragmented by multiple medical specialties. In 1990 the Prevention Committee of the Japan Medical Society of Paraplegia started a nationwide epidemiological survey using a postal questionnaire. The results of the survey in 1990 were reported previously. ${ }^{1}$

The incidence of SCI shows a discrepancy when comparing different reports. Reviewing the medical literature published from 1960 to 1990 , the incidence of newly hospitalised patients was reported to range from 9.2 to 53.4 per million per annum (Table 7). ${ }^{9-16}$

The incidence in Japan from 1990 to 1992 was similar to the respective ones of the recent studies in Australia, ${ }^{16}$ the Federal Republic of Germany ${ }^{11}$ and the USA $^{4,12,13}$ ranging from 27.6 to 53.4 .

One of the characteristic features of SCI in Japan was the greater age at the time of injury. Although a small peak in the age distribution curve was seen in those aged 20 years, the highest peak was observed at 59 .

The high incidence of falls from a height and on level ground was another characteristic feature of SCI in Japan. The rate of patients with falls from a height and on level ground almost reached that of the victims of road traffic accidents.

According to the results of this study, the prevention campaign should be focused mainly on the following subjects and activities: sports, especially diving and motorcycles accidents, for young people; traffic accidents for adults; falling accidents for old people.

The prevention programme has been promoted by the Spinal Cord Injury Prevention Committee of JMSOP since 1990, and a diving education programme was promoted in 1992 for the 5349 high schools on a nationwide scale. There is now a serious commitment to promotion of the prevention of spinal cord injury.

\section{Acknowledgements}

Grateful acknowledgement is made of the research grants received for this study from the Dr Yutaka Nakamura
Memorial Foundation for the Disabled and from the Labour Welfare Corporation.

\section{References}

1 Shingu H, Ikata T, Katoh S, Akatsu T. Spinal cord injuries in Japan: a nationwide epidemiological survey in 1990. Paraplegia 1994; 32: 3-8.

2 Hashimoto $\mathrm{S}$ et al. Response bias in the nationwide epidemiological survey of an intractable disease in Japan. J Epidemiol 1991; 1: 27-30.

3 Frankel $\mathrm{H}$ et al. The value of postural reduction in the initial management of closed injuries of the spine with paraplegia and tetraplegia. Paraplegia 1969; 7: 179-192.

4 DeLilla T. Spinal Cord Injury Program. Central registry statistics. Five-year summary January 1984-December 1988. Division of Vocational rehabilitation, Department of Labor and Employment Security: Florida.

5 THINK FIRST Foundation. The National Head and Spinal Cord Injury Prevention Program. American Association of Neurological Surgeons, Congress of Neurological Surgeons: Illinois, 1990.

6 Wigglesworth EC. Towards prevention of spinal cord injury: the role of a national register. Paraplegia 1988; 26: 389-392.

7 Walsh J. Costs of spinal cord injury in Australia. Paraplegia 1988; 26: 380-388.

8 Yeo JD. Prevention of spinal cord injuries in an Australian study (New South Wales). Paraplegia 1993; 31: 759-769.

9 Gehrig R, Michaelis LS. Statistics of acute paraplegia and tetraplegia on a national scale. Paraplegia 1968; 6: 93-95.

10 Michaelis LS. Epidemiology of spinal cord injury. In: Handbook of Clinical Neurology 25. North-Holland: Amsterdam, 1974, pp 141-143.

11 Botterell EH et al. A model for the fracture care of acute spinal cord injuries. Can J Neurol Sci 1975; 2: 361-380.

12 Kraus F. Injury to the head and spinal cord: The epidemiological relevance of the medical literature published from 1960 to 1978. J Neurosurg 1980; 53: S3-S10.

13 Bracken MB, Freeman DH, Hellenbrand K. Incidence of acute traumatic hospitalized spinal cord injury in the United States, 1970-1977. Am J Epidemiol 1981; 113: 615-622.

14 Biering-Sørensen F, Pedersen V, Clausen S. Epidemiology of spinal cord lesions in Denmark. Paraplegia 1990; 28: 105-118.

15 Chen CF, Lien IN. Spinal cord injuries in Taipei, Taiwan, 1978-1981. Paraplegia 1985; 23: 364-370.

16 Burke DC, Toscano J. Incidence and distribution of spinal cord injury. Menzies Foundation Technical Report 1987; 1: 13-47.

17 Koning W, Frowein RA. Incidence of spinal cord injury in the Federal Republic of Germany. Neurosurg Rev 1989; 12: 562-566. 